Gut, 1986, 27, 283-287

\title{
Why do patients with faecal impaction have faecal incontinence
}

\author{
N W READ AND LAILA ABOUZEKRY \\ From the Tickhill Road Hospital, Doncaster and Department of Surgery, Royal Hallamshire Hospital, \\ Sheffield
}

SUMmaRY To elucidate the phenomenon of faecal incontinence in impacted patients, manometric, radiological and other investigations were carried out in 55 elderly patients, who had impacted masses of faeces in the rectum and were incontinent of faeces and 36 elderly control subjects with no anorectal problems. Maximum basal pressure and the maximum squeeze pressure in impacted patients were not significantly different from elderly controls. Sphincter pressures were no different after disimpaction than they were with faecal masses in situ, suggesting that leakage and soiling were not caused by stretching of the anal ring or prolonged reflex inhibition of anal tone by the faecal mass. The anorectal angle was more obtuse in impacted patients than in elderly controls though there was no greater degree of perineal descent. Anal and perianal sensation was impaired in impacted patients compared with controls. Rectal sensation was also impaired in the impacted patients in that the volume in a rectal balloon that could be perceived by the subject and the volume that gave rise to a desire to defecate were much higher in impacted patients than in controls. The rectal volume required to cause anal relaxation was lower in impacted patients compared with controls though there was no reduction in the volume at which anal relaxation failed to recover its resting tone. Rectal distension elicited external sphincter contractions in $53 \%$ impacted patients compared with $80 \%$ of controls. In conclusion, faecal soiling in patients with faecal impaction is probably related to the combination of an obtuse anorectal angle and the low anal pressures, normally found in the elderly and to impaired anorectal sensation which prevents conscious contraction of the external sphincter when the internal sphincter is relaxed.

Faecal impaction affects a considerable proportion of elderly patients, who are referred for admission to geriatric hospitals. ${ }^{1}$ One of the most distressing complications of faecal impaction is the leakage of mucus and liquid stool. This 'spurious' or overflow incontinence is often explained by the stretching of the anal sphincter caused by the faecal mass $^{2}$ or a reflex reduction in internal sphincter tone by rectal distension, ${ }^{3}$ though few physiological studies of anorectal function have been carried out in patients with faecal impaction.

The aim of this study was to elucidate the pathophysiology of faecal incontinence in impacted patients by conducting manometric, radiological, and other investigations in a total of 55 elderly patients with faecal impaction, all of whom had faecal soiling. The results were compared with data

Address for correspondence: Dr N W Read, Clinical Research Unit, H Floor, Royal Hallamshire Hospital, Sheffield S10 2JG.

Received for publication 24 June 1985. from 36 age and sex matched elderly controls from the same hospital.

\section{Methods}

S U B J E C T S

Tests of anorectal function were carried out in a total of 55 elderly patients with faecal impaction; 28 women, aged between 69 and 95 years (mean $\pm \mathrm{SEM}=82 \pm 1$ years) and 27 men, aged between 70 and 89 years, (mean $\pm S E M=79 \pm 1$ year). All the patients had hard masses of faeces filling the rectum on admission, all gave a history of problems with defaecation, including hard stool, infrequent bowel movements and straining at stool necessitating regular use of laxatives and/or enemata, and all had episodes of soiling with liquid faeces. None of the patients were incontinent to formed stool. Only those patients who were of sufficient mental and physical health to comply with the tests were investigated. Forty six $(84 \%)$ of these patients were 
ambulant, the remainder were confined to a wheelchair. Forty eight patients $(87 \%)$ were of normal mental state and seven were mildly confused though not to the extent of impairing their ability to carry out the tests.

Tests were also carried out on a control group of 36 elderly patients comprising 18 women, aged between 68 and 87 years (mean \pm SEM $=78 \pm 1$ years) and 18 men, aged between 66 and 87 years (mean \pm SEM $=77 \pm 1$ years) who had no history of anorectal disorders or difficulties in defecation.

Patients with faecal impaction were studied on admission while still impacted and then retested a week after disimpaction which was achieved using a combination of laxatives, enemas, and manual evacuation. No further laxatives were given until after the tests were carried out. Control patients were studied on one occasion only, and received no bowel preparation, though each patient was examined to ensure that the rectum was empty of faeces before carying out the test. Only measurements made after disimpaction were compared with values from elderly control patients.

ETHICAL CONSIDERATIONS

The study was approved by the Ethical Committee at Doncaster Area Health Authority in October, 1981. All patients studied, or their relatives in the case of mildly confused patients, gave their informed written consent.

\section{ANORECTAL MANOMETRY}

\section{Sphincter pressures}

Basal and squeeze pressures in the anal canal were recorded by a station pull-through technique using a probe consisting of three low compliance water perfused catheters with distal side openings, $2.5 \mathrm{~cm}$ apart, ${ }^{4}$ and connected to a pneumohydraulic infusion system.

\section{Recto-anal responses}

Distension of the rectum with a balloon normally induces a brief increase in anal pressure, caused by contraction of the external sphincter and a decrease in anal pressure, caused by relaxation of internal anal sphincter tone. ${ }^{5}$ To record these responses, the catheter assembly was inserted so that the middle channel was recording the highest basal pressure. The rectal ampulla was then distended by inflating a balloon situated $7.5 \mathrm{~cm}$ from the middle orifice with $10 \mathrm{ml}$ increments of air. Distension was maintained for 60 seconds. The balloon was then deflated and after a rest period of 60 seconds it was reinflated with the previous volume plus $10 \mathrm{ml}$ of air. Rectal volumes were increased until the balloon was spontaneously expelled, or until anal tone failed to recover while the balloon remained inflated. The presence or absence of sphincter relaxation or contraction was noted, as well as the lowest rectal volume required to elicit relaxation and the lowest volume at which the internal sphincter failed to recover its resting tone.

\section{Balloon distension of the rectum}

Rectal sensations were recorded during distension of the rectum with a cylindrical latex balloon made of $10 \mathrm{~cm}$ of unstretched condom tied around a rigid polyvinyl tube (external diameter $3 \mathrm{~mm}$ ). ${ }^{5}$ The deflated balloon was inserted into the rectum with the aid of a proctoscope and was positioned so that the caudad pole of the balloon was $5 \mathrm{~cm}$ from the anal margin to ensure clearance of the sphincter. The balloon was inflated with air in $50 \mathrm{ml}$ increments every 60 seconds and at each volume the patient was instructed to indicate if he/she felt the balloon. The test was terminated when rectal sensation reached the limit of tolerance or when the balloon was spontaneously expelled.

\section{ANORECTAL RADIOLOGY}

Lateral radiographs of the anorectal region were carried out in 22 patients ( 11 men, 11 women) and 20 controls (nine men, 11 women) to determine the anorectal angulation, the degree of perineal descent below the pubococcygeal line, ${ }^{6}$ and the dimensions of the rectum and anal sphincter. With the patient in the left lateral position and the hips flexed to $90^{\circ}$, $50 \mathrm{ml}$ dilute barium sulphate was injected into the rectum via a narrow catheter. The catheter was then removed and a plastic ball, $2 \mathrm{~cm}$ in diameter was inserted into the rectal ampulla. This was attached to a metal beaded chain which lay in the anal canal and was taped along the natal cleft. In addition a metal paper clip was taped to the perineal skin with one end on the anal margin. Well penetrated lateral radiographs were obtained at rest, during maximum contraction of the sphincter (squeeze) and while the patient strained down. The anorectal angle was measured as the angle between the axis of the rectum, outlined by the barium and the axis of the anal canal indicated by the chain. The amount of perineal descent in each position was measured as the shortest distance from the anorectal angle to a line joining the superior aspect of the symphysis pubis to the tip of the coccyx (pubococcygeal line).

The anal length was measured by counting the number of metal beads in the anal canal. The distance between successive beads on the chain was constant $(0.5 \mathrm{~cm})$.

Finally, the maximum diameter of the radiographic image of the rectum outlined $50 \mathrm{ml}$ of barium was measured. 
ANAL AND PERIANAL SENSATION

The sensation of the anal and perianal skin to pain and light touch were clinically assessed by asking the subject if he could distinguish between pin prick or light touch from the blunt end of the pin. In addition, the ability of the anal canal to discriminate between liquids and gases was estimated by infusing air or water (warmed to $37^{\circ} \mathrm{C}$ ), through a catheter situated with a side opening in the anal canal. ${ }^{7}$ Air and water were each infused in random order for 15 seconds on three separate occasions and the subjects were asked if they could identify the nature of the infusion.

STATISTICAL ANALYS IS

The degree of statistical significance between results from different groups of patients were analysed by Student's $t$ test and the Mann Whitney ' $U$ ' test, depending on whether the data were normally or not normally distributed. The difference between the percentages of patients in each group with certain characteristics was analysed by the four-fold table test with Yates correction.

\section{Results}

ANAL MANOMETRY

Sphincter pressures

There were no significant differences in sphincter pressures between patients with faecal impaction and age and sex matched controls (Table 1).

\section{Recto-anal responses}

All except three controls and two impacted patients

Table 1 Results of anal manometry in patients with faecal impaction and in age and sex matched elderly controls

\begin{tabular}{|c|c|c|c|}
\hline & $\begin{array}{l}\text { Impacted } \\
\text { patients }\end{array}$ & $\begin{array}{l}\text { Elderly } \\
\text { controls }\end{array}$ & $\begin{array}{l}\text { Statistical } \\
\text { significance }\end{array}$ \\
\hline $\begin{array}{l}\text { Age (yr) } \\
\text { (Range } \\
\text { Sex (M:F) } \\
\text { Anal pressures } \\
\end{array}$ & $\begin{array}{l}80 \pm 1 \\
(69-93) \\
15: 16\end{array}$ & $\begin{array}{l}77 \pm 1 \\
(66-86) \\
10: 10\end{array}$ & NS \\
\hline $\begin{array}{l}\text { Mean highest basal } \\
\left(\mathrm{cm} \mathrm{H}_{2} \mathrm{O}\right) \\
\text { Mean highest squeeze } \\
\left(\mathrm{cm} \mathrm{H}_{2} \mathrm{O}\right) \\
\text { Recto anal inhibitory reflex }\end{array}$ & $\begin{array}{l}69 \pm 5 \\
156 \pm 13\end{array}$ & $\begin{array}{l}65 \pm 5 \\
171 \pm 15\end{array}$ & NS \\
\hline $\begin{array}{l}\text { Volume at which anal } \\
\text { relaxation first occurred } \\
(\mathrm{ml}) \\
\text { Volume at which anal } \\
\text { relaxationfailed to recover } \\
\text { (ml) }\end{array}$ & d $17 \pm 4$ & $26 \pm 4$ & $\mathrm{p}<0.05$ \\
\hline
\end{tabular}

Results are expressed as Mean \pm SEM

The degree of statistical significance was assessed by Student's paired $t$ test. NS $=$ not statistically significant $(\mathrm{p}>0.05)$.
Table 2 Comparison of the results of anal manometry in elderly constipated patients before and after disimpaction

\begin{tabular}{|c|c|c|c|}
\hline & $\begin{array}{l}\text { Before } \\
\text { disimpaction }\end{array}$ & $\begin{array}{l}\text { After } \\
\text { disimpaction }\end{array}$ & $\begin{array}{l}\text { Statistical } \\
\text { significance }\end{array}$ \\
\hline \multicolumn{4}{|l|}{ Anal pressures $\left(\mathrm{cm} \mathrm{H}_{2} \mathrm{O}\right)$} \\
\hline $\begin{array}{c}\text { Mean highest basal } \\
\text { Mean highest squeeze } \\
\text { Recto anal inhibitory }\end{array}$ & $\begin{array}{l}64 \pm 7 \\
147 \pm 13\end{array}$ & $\begin{array}{l}69 \pm 5 \\
156 \pm 13\end{array}$ & $\begin{array}{l}\text { NS } \\
\text { NS }\end{array}$ \\
\hline$\underline{\text { reflex }}$ & & & \\
\hline $\begin{array}{l}\text { Volume at which anal } \\
\text { relaxation first } \\
\text { occurred (ml) }\end{array}$ & $18 \pm 3$ & $16 \pm 2$ & NS \\
\hline $\begin{array}{l}\text { Volume at which anal } \\
\text { relaxation failed to } \\
\text { recover }(\mathrm{ml})\end{array}$ & $48 \pm 8$ & $50 \pm 10$ & NS \\
\hline
\end{tabular}

Results are expressed as Mean \pm SEM

The degree of significance was calculated by means of Student's paired $t$ test.

NS $=$ not statistically significant $(p>0 \cdot 05)$.

exhibited reflex relaxation of anal tone on rectal distension. In two controls and one patient, the basal pressure was so low (less than $30 \mathrm{~cm}$ water) that any anal relaxation that might have been present would have been difficult to detect. The minimum rectal volume required to elicit anal relaxation was lower in impacted patients than in controls (Table 1). There was, however, no significant difference in the minimum rectal volume required to prevent recovery of the internal sphincter tone over a period of one minute (Table 1).

Balloon distension of the rectum elicited an initial contraction of the external anal sphincter in $80 \%$ $(16 / 20)$ controls, but only $53 \%(18 / 34)$ of impacted patients $(\mathrm{p}<0 \cdot 05)$.

Anal manometry before and after disimpaction Maximum basal and maximum squeeze sphincter pressures before disimpaction were not significantly different from pressures recorded after disimpaction (Table 2).

Disimpaction did not alter the values for the rectal volume at which anal relaxation first occurred and the rectal volume at which the relaxation failed to recover after one minute (Table 2).

INFLATION OF THE RECTUM WITH A BALLOON Rectal sensation

All control subjects and all except two impacted subjects felt the presence of a balloon during inflation of the rectum. This sensation became continuous as increasing volumes of air were introduced.

The volumes of air that were infused into the rectal balloon before the presence of the balloon was perceived, and before this sensation became 
Table 3 Rectal sensations during balloon distension of the rectum in impacted patients and age and sex matched elderly controls

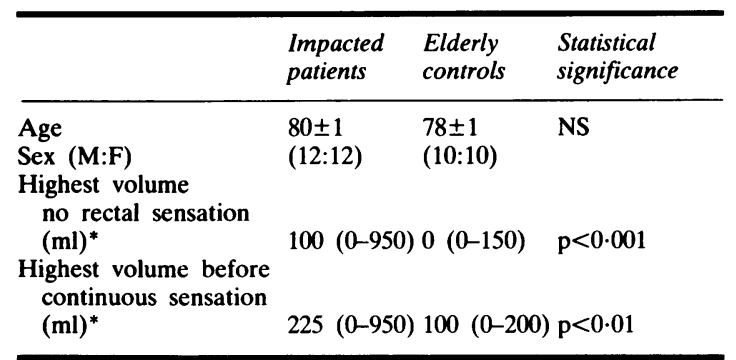

Since rectal volumes date are not normally distributed, the results are expressed as the median with the range of parentheses, and the degree of statistical significance was assessed by the Mann Whitney U test.

*Because in some impacted patients no sensation was felt even at very high distending volumes, the highest volumes infused before sensation was perceived have been compared.

continuous were much higher in the impacted patients compared with age and sex matched controls ( $p<0 \cdot 01$, Mann Whitney U Test) (Table 3). In eight impacted patients the sensations disappeared as the rectum was inflated with larger volumes. This phenomenon was never observed in elderly control patients.

ANAL AND PERIANAL SENSATION Light touch and pain sensation in the anal canal and perianal region was normal in all elderly control patients tested $(n=19)$. In contrast, perianal sensa-

Table 4 Results of anorectal radiology in patients with faecal impaction and elderly controls

\begin{tabular}{llll}
\hline & $\begin{array}{l}\text { Impacted } \\
\text { patients }\end{array}$ & $\begin{array}{l}\text { Elderly } \\
\text { controls }\end{array}$ & $\begin{array}{l}\text { Statistical } \\
\text { significance }\end{array}$ \\
\hline Age (yr) & $83 \pm 1$ & $78 \pm 1$ & NS \\
Sex (M:F) & $13: 12$ & $11: 9$ & \\
Anorectal angle (degrees) & & & \\
$\quad$ Resting & $119 \pm 3$ & $92 \pm 3$ & $\mathrm{p}<0 \cdot 001$ \\
Squeezing & $113 \pm 4$ & $93 \pm 3$ & $\mathrm{p}<0 \cdot 001$ \\
Straining & $130 \pm 4$ & $106 \pm 3$ & $\mathrm{p}<0 \cdot 001$ \\
Anal canal length (cm) & $3 \cdot 2 \pm 0 \cdot 2$ & $2 \cdot 5 \pm 0 \cdot 3$ & $\mathrm{NS}$ \\
Rectal width (cm) & $6 \cdot 1 \pm 0 \cdot 4$ & $5 \cdot 1 \pm 0 \cdot 3$ & NS \\
Perineal descent $(\mathrm{cm})^{*}$ & & & \\
$\quad$ Resting & $-1 \cdot 2 \pm 0 \cdot 2$ & $-1 \cdot 1 \pm 0 \cdot 3$ & $\mathrm{NS}$ \\
Squeezing & $-0 \cdot 8 \pm 0 \cdot 2$ & $-0 \cdot 9 \pm 0 \cdot 6$ & NS \\
Straining & $-2 \cdot 9 \pm 0 \cdot 3$ & $-2 \cdot 6 \pm 0 \cdot 4$ & NS \\
\hline
\end{tabular}

Results are expressed mean \pm SEM.

* =negative sign indicates descent below the pubococcygeal line.

The degree of statistical significance between groups was assessed by Student's paired $t$ test (NS=not significant, $\mathrm{p}>0.05$ ). tion was absent or impaired in 20/27 (74\%) impacted patients $(\mathrm{p}<0 \cdot 01)$, while anal canal sensation was absent or impaired in $21 / 27(77 \%)$ impacted patients $(p<0.01)$. Eleven out of 19 controls $(58 \%)$ could distinguish between gas or liquid in the anal canal. Only seven out of 24 impacted patients $(29 \%)$ could make this distinction $(p>0 \cdot 01)$.

ANORECTAL RADIOLOGY

The anorectal angulation in patients with faecal impaction was significantly more obtuse than in elderly controls at rest, when they actively contracted their anal sphincters and when they strained (Table 4). The obtuse anorectal angle in impacted patients was not related to a change in rectal axis caused by the greater rectal width as there was no significant difference in the width of the rectum outlined by $50 \mathrm{ml}$ barium between impacted patients and controls (Table 4). The anal canal was not significantly longer in impacted patients compared with controls.

Both controls and impacted patients showed some degree of perineal descent at rest, which was increased on straining (Table 4). The degree of perineal descent in patients with faecal impaction was no greater than in control subjects either at rest, on straining, or when they actively contracted the anal sphincter.

\section{Discussion}

The mechanism of faecal incontinence in elderly impacted patients has never been fully investigated. One hypothesis is that the hard dry faecal mass may irritate the rectum causing secretion of mucus, which may be able to leak easily from the rectum because the anal sphincter is stretched by the impacted mass or reflexly inhibited by massive rectal distension. ${ }^{2}$ While the production of mucus may be an important consideration, we found that anal pressures when the rectum contained impacted masses were no lower than in the disimpacted rectum indicating that the anal canal was not stretched and the tone was not chronically inhibited by the impacted masses. Balloon distension of the rectum elicited a normal recto-anal inhibitory reflex in the presence of the impacted mass. Thus the presence of the faecal mass may not actually be a critical factor in causing incontinence.

Elderly patients are liable to develop faecal incontinence because they have weak sphincters, ${ }^{4}$ and some degree of neuropathy of the pudendal nerve. ${ }^{8}$ Incontinence does not often occur in patients with weak sphincters, however, if the stools remain solid and the anorectal angulation is normally acute. Patients with faecal impaction do not have greater 
weakness of the anal sphincter compared with elderly controls, but they do have a more obtuse anorectal angle. The latter suggests a weakness of the pelvic floor, though we were unable to show that the degree of perineal decent was any greater in patients with impaction.

Normal subjects may be able to prevent leakage of faeces because they can perceive the levels of rectal distension which would normally cause relaxation of the internal anal sphincter and consciously contract the external anal sphincter to prevent incontinence. In patients with faecal impaction, rectal sensation is blunted and external sphincter contraction in response to rectal distension only occurred in $53 \%$ patients (compared with $80 \%$ normal controls) and at higher distending volumes than in controls. Thus patients with faecal impaction were less able to guard against the relaxation induced by rectal distension. To add to these difficulties, anal sphincter relaxation occurred at lower levels of rectal distension than in normal volunteers. A similar impairment of rectal sensation has been evoked to explain incontinence in diabetics or patients with meningomyelocoele or children with encopresis. ${ }^{9-12}$ Such patients do not often develop adequate external sphincter responses to rectal distension. ${ }^{9}$ 12-14

The risk of incontinence is further exacerbated in patients with faecal impaction by the impairment of anal sensation. Thus, patients with faecal impaction may have no warning that leakage is about to take place and hence are unable to prevent leakage by conscious contraction of the external sphincter and puborectalis.

Whether the sensory impairment is just part of the normal aging process in some people or whether it is secondary to some other factor cannot be determined from this study. Because prolonged use of laxatives is associated with neuronal degeneration, ${ }^{15}$ one possibility is that prolonged laxative ingestion could cause the sensory impairment in our impacted patients.

\section{References}

1 Geoboes K, Bossaert H. Gastrointestinal disorders in old age. Age Ageing 1977; 6: 197-200.

2 Exton-Smith AN. Constipation in geriatrics. In: Jones FA, Godding EW, eds. Management of constipation. London: Blackwell 1973: 156-175.

3 Schuster MM, Hendrix TR, Mendeloff AI. The internal sphincter response. Manometric studies on its normal physiology, normal pathways and alteration in bowel disease. J Clin Invest 1963; 42: 196-207.

4 Read NW, Harford WV, Schmulen AC, Read MG, Santa Ana CA. Clinical study of patients with faecal incontinence and diarrhoea. Gastroenterology 1979; 76: 747-56.

5 Read MG, Read NW, Barber DC, Duthie HL. Effect of loperamide on anal sphincter function in patients complaining of chronic diarrhoea with faecal incontinence and urgency. Dig Dis Sci 1982; 27: 807-14.

6 Bartolo DC, Read NW, Jarrett JA, Read MG. Difference in anal sphincter function and clinical presentation in patients with pelvic floor descent. Gastroenterology 1983; 85: 68-75.

7 Read MG, Read NW. Role of anorectal sensation and preserving continence. Gut 1982; 23: 345-7.

8 Percy JP, Neill ME, Kandiah TK, Swash M. A neurogenic factor in faecal incontinence in the elderly. Age Ageing 1982; 11: 175-9.

9 Wald A, Tunuguntla AK. Anorectal sensation dysfunction in fecal incontinence and diabetes mellitus. $N$ Engl J Med 1984; 310: 1282-7.

10 Wald A. Biofeedback for neurogenic faecal incontinence: rectal sensation is a determinant of outcome. $J$ Paediatr Gastro Nutr 1983; 2: 302-6.

11 Molnar D, Taitz LS, Unwin OM, Wales JKH. Anorectal manometry results in defaecation disorders. Arch Dis Child 1983; 58: 257-61.

12 Meunier P, Mollard P, Marechal J-M. Physiology of megarectum: the association of megarectum with encopresis. Gut 1976; 17: 224-7.

13 Wald A. Biofeedback therapy for faecal incontinence. Ann Intern Med 1981; 95: 146-9.

14 Cerulli MA, Nikoomanesh P, Schuster MM. Progress in biofeedback conditioning for faecal incontinence. Gastroenterology 1979; 76: 742-6.

15 Smith B. Effects of irritant purgatives on the myenteric plexus in man and the mouse. Gut 1968; 9: 139-43. 